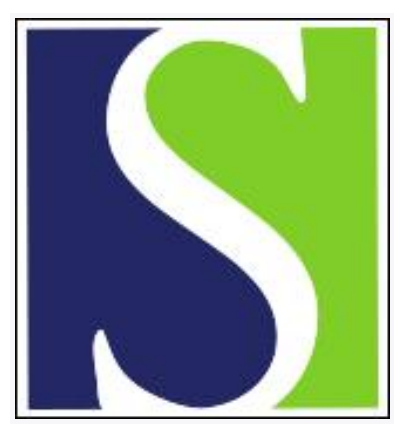

Scand J Work Environ Health 2018;44(4):335-339

https://doi.org/10.5271/sjweh.3749

Published online: 12 Jun 2018, Issue date: 01 Jul 2018

Precarious employment and occupational injuries in the digital age - where should we go from here?

by Marucci-Wellman $\mathrm{H}$

Affiliation: The Workers Compensation Research Institute, Cambridge, MA, USA. hmarucciwellman@comcast.ne]

Refers to the following texts of the Journal: 2005;31(5):329-335

2012;38(6):560-567 2018;44(4):341-350

The following article refers to this text: 2019;45(1):98-99

Key terms: editorial; job insecurity; occupational accident; occupational injury; part-time work; precarious employment; self-employment; temporary work

This article in PubMed: www.ncbi.nlm.nih.gov/pubmed/29893979 


\section{Precarious employment and occupational injuries in the digital age - where should we go from here?}

There is growing demand for a clearer understanding of whether precarious work is a social determinant of health (1-5) and whether non-standard workers with less job security are more vulnerable to adverse safety and health outcomes. In their systematic review published in the current issue of the Scandinavian Journal of Work Environment and Health, Koranyi et al (6) define "precarious employment" as a multidimensional set of unfavorable work characteristics experienced in various degrees by workers with the common denominator of loss of security in some domain. Their review makes an important contribution to this area by summarizing the existing scientific research on the relationship between precarious work and risk of occupational injury.

As a vulnerable working population, precarious workers have consistently been a topic of concern since the late 1980 s $(5,7)$. Yet the review by Koranyi et al $(6)$ demonstrates unequivocally the paucity of research studies performed over the last two decades addressing the subject. Four dimensions of precarious work were defined in the study and these, along with their corresponding search constructs, form the basis of the review and include (i) length of employment (exposed or not to: temporary employment, casual employment, working for subcontractor or temp agency, hourly pay); (ii) at work characteristics (exposed or not to: work time control, fixed work schedule); (iii) income (exposed or not to: part time, multiple jobs, wages), and (iv) labor rights (exposed or not to: insurance benefits, unionization, job insecurity precarious career). Given the wide range of search terms used, it was surprising that only 80 research articles were identified for full review following searches in PubMed, Scopus and Web of Science databases (articles published 1997-2017), and only 17 articles were selected following full review to form the scientific basis of the evidence between precarious work and risk of work-related injury.

Most of the selected studies demonstrated that there is likely a positive association between these dimensions of precarious work and work-related injury. However, it remains unclear whether the "loss of security" is a characteristic of non-standard work (multiple job holding, or part-time, temporary or contract work) that increases the risk of a work-related injury. Most studies evaluated non-standard work characteristics as implicit of precarious work but did not directly address the question.

Three studies were found that focused on factors directly related to "loss of security": lack of insurance benefits (8), job insecurity (9), and precarious career (10). Of these factors, two had statistically significant associations with work-related injury [eg, insurance benefits, risk ratio (RR)/odds ratio (OR) 1.50 (95\% confidence interval [Cl]: 1.19-1.88), and precarious career RR/OR 1.41 (95\% Cl 1.34-1.48)]; however, job insecurity showed a positive, but non- significant association, RR/OR of 1.55 .

Work in multiple jobs and working for temporary agencies were the two areas of non-standard work arrangements providing the strongest evidence of elevated risk of work-related injury. All four studies on multiple job holding (11-14) reported increased risk of work-related injury when working in multiple jobs as compared with single jobs (with 3 of the 4 being statistically significant). Dong et al's longitudinal study (12) demonstrated a strong dose-response relationship where every additional job resulted in increased risk to a cohort of construction workers. Both of the two studies on work in temporary agencies $(15,16)$ reported increased risk when working in temporary agencies compared to all industry (Finland and Washington State, USA).

Although work in temporary employment was the most common exposure studied ( 6 of 17 articles) and is believed by Koranyi et al (6) to be the "central dimension" of precarious employment, only one of the studies looking specifically at this work group found a significant association. The article by Bena et al (17) was perhaps the most relevant and convincing article in the review. This study investigated how working as a subcontractor (versus a contractor) and length of employment contract were associated with risk of work-related injury in a 
cohort of 9000 construction workers employed on a high-speed train construction site in Italy. The shorter the length of a worker's employment contract, the higher the risk of injury: the RR was over twice as high for those with a 6-month contract (as compared with a 2-year contract), 1.7 times higher for 1-year contract, and 1.5 times higher for 1.5-year contract. The associations were strong and $\mathrm{Cl}$ narrow and there also appeared to be a strong dose-response relationship. Additionally, length of contract is an objective exposure metric and likely related to job insecurity. Other studies evaluated only very broad exposure categories of work in temporary versus permanent employment (with no detail on the type of work), which may be why only weak associations were found (ie, we don't know whether there may be unbalanced occupational hazards in the temporary versus permanent employment groups).

Despite the publicity and reporting of fatalities of workers in temporary work assignments $(18,19)$ the research evidence to date has been inconclusive on whether this work group is at elevated risk for injury. Much stronger studies in this area are needed which better control for the role of occupational exposures or other job characteristics (such as job tenure, socioeconomic status) known to be related to temporary work and workrelated injury to avoid confounding or mediating risk.

Alali et al (9) was the only study to simultaneously investigate job insecurity and temporary versus permanent contract work status. The RR for both these risk factors, in their study of Belgium workers, was statistically insignificant: job insecurity had a positive association while temporary contract work appeared protective. This may indicate that job insecurity mediates or confounds the relationship between holding a temporary work contract and work-related injury or possibly is on the causal pathway or these risk factors may be too highly correlated to study together.

The majority of the 17 studies focused on only a single aspect of non-standard work; however, a worker frequently experiences many, simultaneous non-standard work exposures. For instance, multiple job holders are more likely than single job holders also to be on-call workers, independent contractors, and those working the evening shift or some other non-regular schedule (13). Therefore, while some of these workers may be at very high risk due to being exposed to multiple exposures known to be related to work-related injury (eg, long work hours, working the night shift, insufficient wages in a primary job) others may be working in a second part-time job to pursue a hobby or special interest and may not be exposed to job insecurity, high work demands or be at elevated risk at all. Currently, these two multiple job holder exposure groups with very different exposure dimensions are being grouped together, which may obscure the true magnitude of risk for the more vulnerable work group.

The "at work characteristics" dimension of precarious work, which includes the constructs of work time control and fixed work schedule, did not appear to be comprehensively addressed in this review. There were only two search terms related to this topic, "inconvenient hours" and "part-time work." Many workers are now exposed to many different kinds of precarious work schedules such as just-in-time scheduling, fluctuating work hours (20) or work in the early morning or overnight. While the relationship between shift work, long work hours and workrelated injury have been well studied and shown to increase risk of injury (21-31), they need to be included as covariates in studies along with other non-standard work characteristics in order to control for confounding or effect modification.

While there appears to be enough evidence to conclude that non-standard and precarious work described by Koranyi et al (6) is associated with work-related injury, critical areas still need to be addressed in order for interventions to be developed. Etiologic evidence on specific populations and mechanisms (fixed and transient factors) leading to work-related injuries for these populations (4) is needed. We also need to understand the interaction between risk associated with "job insecurity" or job dissatisfaction and structural components of non-standard working creating vulnerability (such as fragmentation of the working day, flexible work schedules or job tenure).

Many of these non-standard work characteristics are correlated and, therefore, the highest-risk groups are likely to be only small subsets of the work groups studied (ie, multiple job holders who are working in temporary assignments and where their second job is at night). These high risk groups may be difficult to study and find statistical associations due to sample size constraints. Low prevalence of high risk exposures as well as rela- 
tively rare incidence of some work-related injuries pose challenges as well. One potential approach may be a case-control design with nested case crossover, which would have the added benefit of studying both fixed and transient risk factors (such as work scheduling) and controlling for confounding or effect modifying factors (eg, age, gender, education, income, tenure, employer size). The benefit of the nested case-crossover design would allow for easily identified cases (through emergency departments or trauma centers) to efficiently be used as their own controls and allow for studying transient exposures, which could include the transitions to new job schedules and job forms.

National-level surveillance of the ever-growing precarious workforce will require: (i) defining a set of standard characteristics that should be collected simultaneously which cover all aspects of non-standard work and precariousness, (ii) changing how we collect employment information, (iii) implementing surveillance systems which are able to also collect characteristics of workers with outcomes in this same format; and (iv) designing and carrying out research that can identify enough cases and optimize power to properly study all potential factors simultaneously.

Currently, we have only very imprecise and/or local estimates of the prevalence of new forms of work. Annual employment estimates are collected using antiquated systems designed to gather employment data with the primary objective of tracking and understanding unemployment in societies. Typically, workers are asked if they were employed in the last week, and then, if yes, what was the industry and occupation that they worked in for their primary job. In order to gather employment data on the many new forms of work, as well as on multiple jobs and the precarious nature of work, more questions are required. The Bureau of Labor Statistics (32) US Contingent Worker Supplement to the Current Population Survey is a supplemental survey that does address some of the issues. However, this is treated as a supplemental intermittent survey and has only been issued very sporadically; last year (2017) was the first time it was administered since 2005.

Questions need to be developed to provide understanding at a detailed level on both non-standard work and the level of precariousness for those with work-related injury. Since workers can be working in multiple nonstandard ways, questions need to be asked in a very direct manner (with yes/no options) for both non-standard employment (33) and levels of job insecurity.

It is evident from this review that a direct measure of job insecurity was missing in many of the prior studies. This exposure element is difficult to objectively assess, although low wages and length of contract may be close markers. The Employment Precariousness Scale (EPRES) (34), which Koranyi et al employed, appears to be a useful and tested tool for assessing job insecurity going forward. This tool has demonstrated high sensitivity to worker vulnerability, employment instability, and levels of precariousness.

For about the last 30 years, vast changes in the world of work have occurred at an incredibly rapid pace. As developing nations have been industrializing, modern western nations have been de-industrializing. Globalization, along with de-industrialization, has resulted in rapid growth of the service sector and a decline in manufacturing in advanced economies. Even more recent and impactful has been the dramatic shift away from stable, fixed and permanent employment arrangements to "flexible "and precarious work forms - the most recent of that being work in the "gig" economy, a term borrowed from the music industry which refers to a job with no long-term connection to a particular business (35).

With the participation of as many as $25-40 \%$ workers in European/Scandinavian countries (36-37) and 15-20\% of US workers and growing (33) in such employment, there is a real need to understand risk factors unique to these new forms of employment. In this new phase of flexible employment, workers are working in hazardous jobs without the appropriate protections in place. As Koranyi et al (6) state, "Regarding health outcomes, it is even questionable if having a precarious job is better than no job at all. To improve work-related health on a structural level it is of great importance that policy changes are guided by scientific evidence..." This review pro- 
vides support to implement better tools for surveillance and high quality research for these emerging, potentially higher risk and vulnerable work groups.

\section{Acknowledgement}

The author acknowledges Dr. David Lombardi and Ms Margaret Rothwell for their invaluable reviews and critical feedback on this editorial.

This editorial reflects the views of the author and not necessarily those of the Workers Compensation Research Institute.

\section{References}

1. Benach J, Benavides FG, Platt S, Diez-Roux A, Muntaner C. The health-damaging potential of new types of flexible employment: A challenge for public health researchers. American Journal of Public Health 2000; 90(8):1316. https://doi. org/10.2105/AJPH.90.8.1316

2. Benach J, Muntaner C. Precarious employment and health: developing a research agenda. J Epidemiol Community Health. 2007;61(4):276-7. https://doi.org/10.1136/jech.2005.045237

3. Benach J, Vives A, Amable M, Vanroelen C, Tarafa G, Muntaner C. Precarious employment: understanding an emerging social determinant of health. Annu Rev Public Health. 2014;35:229-53. https://doi.org/10.1146/annurevpublhealth-032013-182500

4. Benach J, Vives A, Tarafa G, Delclos C, Muntaner C. What should we know about precarious employment and health in 2025? Framing the agenda for the next decade of research. Int J Epidemiol. 2016;45(1):232-8. Erratum in: Int J Epidemiol 2016;45(3):969 https://doi.org/10.1093/ije/dyv342

5. Landsbergis PA, Grzywacz JG, LaMontagne AD. Work organization, job insecurity, and occupational health disparities. Am J Ind Med. 2014;57(5):495-515. https://doi.org/10.1002/ajim.22126

6. Koranyi I, Jonsson J, Rönnblad T, Stockfelt L, Bodin T. Precarious employment and occupational accidents and injuries - a systematic review. Scand J Work Environ Health. 2018;44(4):341-350. https://doi.org/10.5271/sjweh.3720

7. International Labor Organization (ILO). From precarious work to decent work: outcome document to the workers' symposium on policies and regulations to combat precarious employment. Geneva: International Labour Office, Bureau for Workers'Activities, 2012.

8. Berdahl TA, McQuillan J. Occupational Racial Composition and Nonfatal Work Injuries. Soc Probl. 2008;55(4):549-72. https://doi.org/10.1525/sp.2008.55.4.549

9. Alali H, Abdel Wahab M, Van Hecke T, Braeckman L. Work accident victims: a comparison between non-standard and standard workers in Belgium. Int J Occup Environ Health. 2016;22(2):99-106. https://doi.org/10.1080/10773525.2016. 1168588

10. Giraudo M, Bena A, Leombruni R, Costa G. Occupational injuries in times of labour market flexibility: the different stories of employment-secure and precarious workers. BMC Public Health. 2016; 16:150. https://doi.org/10.1186/s12889-0162834-2

11. Dong X. Long workhours, work scheduling and work-related injuries among construction workers in the United States. Scand J Work Environ Health. 2005;31(5):329-35. https://doi.org/10.5271/sjweh.915

12. Dong XS, Wang X, Largay JA. Occupational and nonoccupational factors associated with work-related injuries among construction workers in the USA. Int J Occup Environ Health. 2015;21(2):142-50. https://doi.org/10.1179/204939671 4Y.0000000107

13. Marucci-Wellman HR, Willetts JL, Lin TC, Brennan MJ, Verma SK. Work in multiple jobs and the risk of injury in the US working population. Am J Public Health. 2014;104(1):134-42. https://doi.org/10.2105/AJPH.2013.301431

14. Alali H, Braeckman L, Van Hecke T, De Clercq B, Janssens H, Wahab MA. Relationship between non-standard work arrangements and work-related accident absence in Belgium. J Occup Health. 2017; 59(2):177-86. https://doi.org/10.1539/ joh.16-0119-OA

15. Hintikka N. Accidents at work during temporary agency work in Finland - Comparisons between certain major industries and other industries. Saf Sci. 2011;49(3):473-83. https://doi.org/10.1016/j.ssci.2010.11.004

16. Smith CK, Silverstein BA, Bonauto DK, Adams D, Fan ZJ. Temporary workers in Washington State. Am J Ind Med. 2010;53(2):135-45. https://doi.org/10.1002/ajim.20728

17. Bena A, Berchialla P, Debernardi ML, Pasqualini O, Farina E, Costa G. Impact of organization on occupational injury risk: evidence from high-speed railway construction. Am J Ind Med. 2011;54(6):428-37. https://doi.org/10.1002/ajim.20939 
18. OSHA. Recommended Practices: Protecting Temporary Workers. DHHS (NIOSH) Publication Number 2014-139 OSHA 3735-2014. Occupational Safety and Health Administration. Available at https://www.osha.gov/Publications/OSHA3735. pdf. 2014.

19. Weil D. The Fissured Workplace: Why Work Became So Bad for So Many and What Can Be Done to Improve It. Cambridge, MA: Harvard University Press, 2014. https://doi.org/10.4159/9780674726123

20. Lambert SJ, Fugiel PJ, Henly JR. Precarious Work Schedules among Early-Career Employees in the US: A National Snapshot. Research brief issued by EINet (Employment Instability, Family Well-being, and Social Policy Network) at the University of Chicago: http://ssascholars.uchicago.edu/einet. August 27, 2014.

21. Smith L, Folkard S, Poole C. Increased injuries on night shift. Lancet. 1994;344:1137-39. https://doi.org/10.1016/S01406736(94)90636-X

22. Folkard S. (1997). Black times: Temporal determinants of transport safety. Accident Anal Prev. 29:417-30. https://doi. org/10.1016/S0001-4575(97)00021-3

23. Folkard S, Tucker P. Shift work, safety and productivity. Occup Med (Lond). 2003;53:95-101. https://doi.org/10.1093/ occmed/kqg047

24. Dembe AE, Erickson JB, Delbos RG, Banks SM. The impact of overtime and long work hours on occupational injuries and illnesses: New evidence from the United States. Occup Environ Med. 2005;62:588-97. https://doi.org/10.1136/ oem.2004.016667

25. Folkard S, Lombardi DA. Modeling the impact of the components of long work hours on injuries and "accidents". Am J Ind Med. 2006;49:953-63. https://doi.org/10.1002/ajim.20307

26. Basner M, Fomberstein KM, Razavi FM, Banks S, William JH, Rosa RR, et al. American Time Use Survey: Sleep time and its relationship to waking activities. Sleep. 2007;30:1085-95. https://doi.org/10.1093/sleep/30.9.1085

27. Lombardi DA, Folkard S, Willetts JL, Smith GS. Daily sleep, weekly working hours, and risk of work-related injury: US National Health Interview Survey (2004-2008). Chronobiol Int. 2010;27:1013-30. https://doi.org/10.3109/07420528.20 10.489466

28. Lombardi DA, Wirtz A, Willetts JL, Folkard S. Independent effects of sleep duration and body mass index on the risk of a work-related injury: Evidence from the US National Health Interview Survey (2004-2010). Chronobiol Int. 2012;29:55664. https://doi.org/10.3109/07420528.2012.675253

29. Williamson A, Lombardi DA, Folkard S, Stutts J, Courtney TK, Connor JL. The link between fatigue and safety. Accident Anal Prev. 2011;43:498-515. https://doi.org/10.1016/j.aap.2009.11.011

30. Arlinghaus A, Lombardi DA, Courtney TK, Christiani DC, Folkard S, Perry MJ. The effect of rest breaks on time to injury: A study on work-related ladder-fall injuries in the United States. Scand J Work Environ Health. 2012;38(6):560-67. https:// doi.org/10.5271/sjweh.3292

31. Basner M, Spaeth AM, Dinges DF. Sociodemographic characteristics and waking activities and their role in the timing and duration of sleep. Sleep. 2014; 37:889-906. https://doi.org/10.5665/sleep.4238

32. Bureau of Labor Statistics (BLS). Contingent and Alternative Employment Arrangements, February 2005. Economic News Release: US Department of Labor, July 27, 2005.

33. Katz LF, Krueger AB. The Rise and Nature of Alternative Work Arrangements in the United States, 1995-2015. March 29, 2016. NBER Working Paper No. 22667. National Bureau of Economic Research, September 2016. https://doi.org/10.3386/ w22667

34. Vives A, Amable M, Ferrer M, Moncada S, Llorens C, Muntaner C, et al. The Employment Precariousness Scale (EPRES): psychometric properties of a new tool for epidemiological studies among waged and salaried workers. Occup Environ Med. 2010;67(8):548-55. https://doi.org/10.1136/oem.2009.048967

35. Abraham KG, Haltiwanger J, Sandusky K, Spletzer JR. Measuring the Gig Economy. Presentation given to the Society of Labor Economists, May 6, 2016. US Census Bureau.

36. Broughton A, Green M, Rickard C, Swift S, Eichhorst W, Tobsch V. Precarious Employment in Europe: Patterns, Trends and Policy Strategies. Directorate General for Internal Policies, Policy Department A: Economy and Scientific Policy, European Parliament, PE 587.303. 2016. Available at: http://www.europarl.europa.eu/RegData/etudes/STUD/2016/587285/ IPOL_STU(2016)587285_EN.pdf

37. Jain A, Hassard J. Precarious work: definitions, workers affected and OSH consequences. OSH/WIKI. London 2018. Available at https://oshwiki.eu/wiki/Precarious_work:_definitions,_workers_affected_and_OSH_consequences

\author{
Helen Marucci-Wellman \\ Senior analyst/epidemiologist \\ The Workers Compensation Research Institute \\ Cambridge, MA \\ USA
}

[Email: hmarucciwellman@comcast.net] 
